\title{
Lembrar, esquecer, memorizar, rememorar: memória e modos de existência
}

\author{
Mariana Luz Pessoa de Barros
}

Resumo: Nas obras autobiográficas, conforme o narrador relata suas memórias no tempo da narração, rememora o passado adormecido e materializa as lembranças desse passado no texto. Conduz-nos, desse modo, nos termos da semiótica tensiva, da dêixis da ausência para a da presença. Entretanto, na história contada, as experiências vividas pelo sujeito do narrado caminham no sentido contrário, da presença para a ausência, adentrando o esquecimento e também a memória. Nosso objetivo é discutir como esses dois percursos são encenados nos discursos autobiográficos - o percurso da lembrança e o percurso do esquecimento -, bem como seus efeitos de sentido.

Palavras-chave: discurso autobiográfico; modos de existência; campo de presença; semiótica discursiva.

Abstract: Remember, forget, memorize, recall: memory and modes of existence - In autobiographical works, as the narrator tells his memories within narration time, he remembers his asleep past and also materializes his remembrances turning them into a text. In this way he leads us from absence deixis to presence deixis (both terms in tensive semiotics). However, the subject's experiences take the opposite direction (from presence to absence) in narrated past, entering both forgetfulness and memory. This paper aims to discuss how these two directions or "pathways" (remembrance and forgetfulness) as well as their meaningful effects are performed in autobiographical discourses.

Keywords: autobiographical discourses; modes of existence; field of presence; discursive semiotics.

Nas obras autobiográficas, o passado é recriado textualmente. No entanto, não se trata do passado tal como foi, mas daquele que ficou na memória ou ainda que foi selecionado pelo narrador - de forma mais consciente ou menos - para tornar-se escritura. Assim, o que temos nos gêneros autobiográficos são memórias feitas de linguagem e discurso, submetidas, portanto, a coerções diversas dadas pelos usos linguísticos e discursivos e pelas relações estabelecidas entre os parceiros da comunicação. 
Cada modo de organizar discursivamente a memória é, dessa forma, revelador de relações de comunicação específicas entre o enunciador e o enunciatário - que podem ser compreendidos respectivamente como o autor e o leitor projetados pelo enunciado, sujeitos "de papel" e não pessoas de carne e osso. É preciso ainda esclarecer que entendemos a comunicação de forma não restritiva, como "a ação dos homens sobre outros homens, criando relações intersubjetivas e fundando a sociedade" (FIORIN, 2004, p. 14). Sob o ponto de vista da semiótica discursiva, qualquer texto, pertencente ao que se vem denominando comunicação de massa ou não, estabelece relações comunicativas entre um enunciador e um enunciatário, independentemente de serem eles actantes coletivos ou individuais.

No caso dos gêneros autobiográficos, para compreendermos a interação entre essas duas instâncias - o enunciador e o enunciatário -, é preciso dar conta das diversas possibilidades de funcionamento discursivo da memória, das quais decorrem diferentes formas de o enunciador agir sobre o enunciatário. Tendo isso em vista, este artigo procura, no quadro da semiótica discursiva, entender o modo como a memória se organiza nos discursos autobiográficos, a partir do exame de figuras que contribuem para a sua construção, como a lembrança, o esquecimento, a memorização e a rememoração.

Focaremos nossa análise em Baú de ossos (2000), de Pedro Nava, que, além de tratar-se de obra paradigmática no que se refere à produção memorialística brasileira, está repleta de passagens que mostram a memória em ação e ainda a tematizam, algo de grande valia num trabalho preocupado em discutir sua estruturação discursiva.

Apesar de seus aspectos singulares, esse primeiro volume das memórias do médico e escritor Pedro Nava possui algumas características comuns a obras de cunho autobiográfico, como: efeito de identidade entre protagonista e narrador, narrador e enunciador, enunciador e protagonista; relato retrospectivo em prosa; um narrador que, no presente da narração, recorda-se do passado e o transforma em narrativa; um protagonista recordado que vive suas experiências no tempo pretérito do narrado; e temática da "minha vida". A análise das relações entre as duas temporalidades - da narração e do narrado - e ainda entre os dois sujeitos - o narrador recordador e o protagonista recordado - terá papel essencial no enfrentamento da problemática aqui proposta, conforme pretendemos mostrar. Isso porque o passado reconstruído nas obras autobiográficas, mesmo no interior de cada obra, não pode ser visto como único, já que é percebido pelos diferentes eus que com ele se relacionam: o enunciador, o narrador e o protagonista. Cada um desses sujeitos constitui-se como um centro dêitico, que estabelece relações de espaço e de tempo, bem como é fonte de percepções e de avaliações, que podem apresentar maior ou menor afinidade.

Com relação à abordagem teórica, daremos centralidade neste estudo à noção de campo de presença, tal como foi desenvolvida pela vertente tensiva da semiótica (FONTANILLE; ZILBERBERG, 2001), a partir das propostas de Merleau-Ponty. Tal noção vem-se mostrando muito produtiva para o tratamento de um aspecto essencial da memória: 
sua relação estreita com a percepção - algo já apontado por inúmeros pesquisadores que se dedicam a essa temática e que aparece de maneira bastante explícita na obra de Pedro Nava, conforme pretendemos mostrar a seguir.

\section{Memória e percepção nos discursos autobiográficos}

Para que possamos compreender a maneira como a percepção se relaciona com a memória nas obras autobiográficas, teceremos alguns comentários iniciais sobre fragmentos do primeiro dos sete volumes das memórias de Pedro Nava. Nessa obra, o narrador tanto "encena" momentos em que sua memória é posta em funcionamento, quanto suspende a narração para refletir sobre ela:

Uns fatos voltam ao sol da lembrança com a rapidez dos dias para os mundos de pequena órbita. Vivem na memória. Perto do astro-rei, como Vênus e Marte. Há os distantes, como Saturno. Outros, cometas, passam roçando e queimando; depois somem em trajetórias mergulhadas nas distâncias espaciais do esquecimento. Tocam, com suas caudas, galáxias perdidas na mais prodigiosa altura das alturas; voltam, novamente, ameaçando arrasar tudo com o rabo de fogo. Como face de lua, aquele prato imaculado e duro. De ágata. Relutâncias diante do mingau transbordante. Comido aos poucos, iam aparecendo na borda as letras do alfabeto e os números de 0 a 9 (NAVA, 2000a, p. 233).

Com uma linguagem bastante metafórica, o narrador adulto procura, no trecho citado, compreender o "vaivém" das lembranças. A passagem introduz a descrição da imagem emersa do prato de louça durante a infância, oportunidade para viagens na imaginação.

Para que os tempos da meninice venham à tona, o sujeito recordador precisa entrar em contato com algum elemento presente capaz de fazer desencadear uma série de associações sensoriais. Entre os estímulos possíveis, aqueles que despertam o sentido da visão são os mais explorados nos escritos autobiográficos de Nava, embora cheiros, sabores, texturas e sons também possam atrair os blocos de memória para a superfície do presente e, assim, do texto. É o que encontramos no fragmento seguinte, em que o narrador se mostra bastante impactado pela rememoração:

Para mim, roçar os dentes num pedaço de batida é como esfregar a lâmpada de Aladim - abrir os batentes do maravilhoso. Reintegro imediatamente a Rua Aristides Lobo, no Rio; a Direita, em Juiz de Fora; a Januária, em Belo Horizonte - onde chegavam do Norte os caixotes mandados por Dona Nanoca com seus presentes para os netos. Docemente mastigo, enquanto uma longa fila de sombras vem dos cemitérios para tomar o seu lugar ao sol das ruas e à sombra das salas amigas: passam lá fora o Coronel Germano e a Dona Adelina Corroti numa conversa de palavras sem som. Meu pai entra sorrindo e seus pés não fazem barulho na escada. Minha mãe chega em silêncio e tira duma jarra um molho 
de cravinas translúcidas para pôr no coque. A vida recomeça como a projeção (no vácuo!) de um filme de cinema mudo.

O céu, sem uma nuvem, é lindo e desolado como um deserto. Pesa o sol a pino despejando luz tão branca e densa que se tem a impressão de vê-la descer em lenta pulverulência. O calor do meio-dia seria insuportável sem o vento que não para. Ele entra pelas portas e janelas abertas - em corrente, em tromba, em golpes, em lufadas e rodamoinhos e numa de suas rajadas chega o moreno amado, vestido de claro, colarinho largo e o vasto chapéu Manilha que lhe empastou, na testa, a cabeleira revolta. É hora da sesta e do café depois da metade do seu trabalho (ibidem, p. 27).

Ao morder a batida feita por sua avó - espécie de rapadura que costumava comer quando menino -, o adulto vive uma "invasão" de figuras que povoavam um outrora. Utiliza o tempo presente ("passam", "entra", "fazem", "chega", "tira" etc.) no lugar do pretérito perfeito e do pretérito imperfeito, presentificando o passado na linguagem e criando os efeitos de aproximação do passado em relação ao tempo da enunciação e, portanto, de subjetividade (FIORIN, 1996, p. 207-208)'. A sequência de orações coordenadas, por um lado, ajuda a compor a lembrança como bloco único, formado por relações de contiguidade; por outro, caracteriza o texto de tipo descritivo e produz o efeito de que o narrador escreve sobre aquilo que vê, sobre o que acontece diante de seus olhos, reforçando a presentificação. A metáfora do "filme de cinema mudo" corrobora nossas afirmações.

Embora o início desse fragmento de memória possua uma organização narrativa (quanto ao tipo textual), já que dispõe os fatos numa sequência temporal, ele está sob o domínio da descrição, que constrói no texto a maneira como os eventos são percebidos. As ações apresentadas desenvolvem-se, no geral, de forma concomitante. Especialmente no segundo parágrafo citado, a ênfase recai sobre as qualidades dos objetos. Tanto a concomitância temporal quanto a exploração da dimensão sensível são elementos característicos da descrição. Bertrand (2003, p. 114), ao refletir sobre os diferentes tipos de texto a partir da questão do ponto de vista, afirma: "no discurso descritivo, o ponto de vista se refere diretamente à atividade perceptiva". Mostra assim a relação muito próxima que existe entre a atividade perceptiva e a descrição, o que justifica o emprego desse tipo textual em obras autobiográficas, que reconstroem textualmente não apenas as lembranças do passado - repletas de representações sensoriais -, mas também o modo como são desencadeadas a partir de percepções do mundo presente e a maneira como afetam de forma sensível o sujeito recordador.

1 O uso de um tempo com o valor de outro apaga a oposição entre os dois, resultando numa neutralização dos termos da categoria do tempo, o que resulta em efeitos de sentido observáveis nos discursos. Nesse caso, ocorre a substituição de tempos que possuem como referência um momento pretérito não-concomitante ao presente da enunciação - pretérito perfeito 2 e pretérito imperfeito (FIORIN, 1996) - por tempos concomitantes ao agora, o que gera essa aproximação do passado em relação ao momento da enunciação, bem como o efeito de que se passa de uma temporalidade objetiva, porque sem relação com o momento da enunciação, a uma temporalidade subjetiva. É preciso dizer ainda que Fiorin (ibidem) diferencia o pretérito perfeito 2, que marca concomitância em relação a um momento de referência passado, do pretérito perfeito 1, que indica anterioridade em relação a um momento de referência presente. 
No entanto, não é apenas a lembrança que atua sobre a memória ou que diz respeito à percepção. O esquecimento, figura frequente na obra de Nava, também opera sobre as experiências vividas, dificultando, muitas vezes, a rememoração. No primeiro fragmento citado, por exemplo, o narrador mostra que o esquecimento torna os fatos do passado ("cometas") distantes, ou seja, ele é responsável pelo enfraquecimento da presença das imagens do passado, causando até mesmo o seu aparente sumiço: "Outros, cometas, passam roçando e queimando; depois somem em trajetórias mergulhadas nas distâncias espaciais do esquecimento" (NAVA, 2000a, p. 233).

Como a outra face da lembrança na constituição da memória, o esquecimento provoca ainda a supressão de intervalos, algo que possibilita a fuga das coerções da temporalidade cronológica e linear, bem como da organização sintagmática do espaço, já que faz o menino passar de um dia a outro e de um lugar a outro, sem levar em conta o que transcorreu entre eles:

Não é bem como eu disse antes, que anoitecia aqui, para acordar ali. A memória é que suprimia intervalos e permitia que eu passasse sem interrupção, da noite da Rua Direita aos terreiros ensolarados de secar café, em Santa Clara; da primavera da chácara do seu Carneiro ao verão do Rio Comprido e aos frios do Paraibuna (ibidem, p. 227).

É importante notar que os saltos no tempo e no espaço dizem respeito tanto à maneira como a criança percebia o tempo e o espaço quanto ao modo como o narrador percebe o passado, corroborando mais uma vez nossas afirmações iniciais a respeito da estreita relação entre a percepção e a memória encenada nos textos autobiográficos.

Com vistas a discutir tal relação, procuraremos analisar o que ocorre num nível mais abstrato, no que diz respeito à geração do sentido, quando a lembrança, o esquecimento, a rememoração e a memorização entram em cena. Para tanto, partiremos da noção de campo de presença, concebida como "o domínio espaciotemporal em que se exerce a percepção, e, por outro, as entradas, as estadas, as saídas e os retornos que, ao mesmo tempo, a ele devem seu valor e lhe dão corpo" (FONTANILLE; ZILBERBERG, 2001, p. 125). Toda grandeza que penetra no campo é avaliada a partir da relação entre sua extensão (dimensão inteligível) e a intensidade da percepção de um sujeito (dimensão sensível).

Tal campo é organizado a partir dos intervalos entre a presença e a ausência, tanto do sujeito quanto do objeto semiótico. Podemos, por exemplo, encontrar nos discursos sujeitos tônicos, muito atentos ao mundo, ou sujeitos átonos, dispersos e desinteressados. Do ponto de vista dos objetos, há aqueles que convocam mais a atenção dos sujeitos ou ainda que os afetam com maior intensidade, bem como aqueles que nem são notados.

Estamos aqui já tratando do que a semiótica entende por modalização existencial, que é construída a partir da categoria presença/ausência, cujas modulações fornecem a primeira modalização das relações perceptuais entre o sujeito e o objeto 
(FONTANILLE; ZILBERBERG, 2001, p. 97-98). Entre a presença excessiva (o sujeito completamente tomado pelo objeto) e a total ausência (o sujeito que praticamente deixa de ser sujeito por estar inteiramente desligado dos objetos), que apontam para a perda de sentido, estabelecem-se os diferentes modos da existência semiótica, que podem ser visualizados no esquema apresentado a seguir:

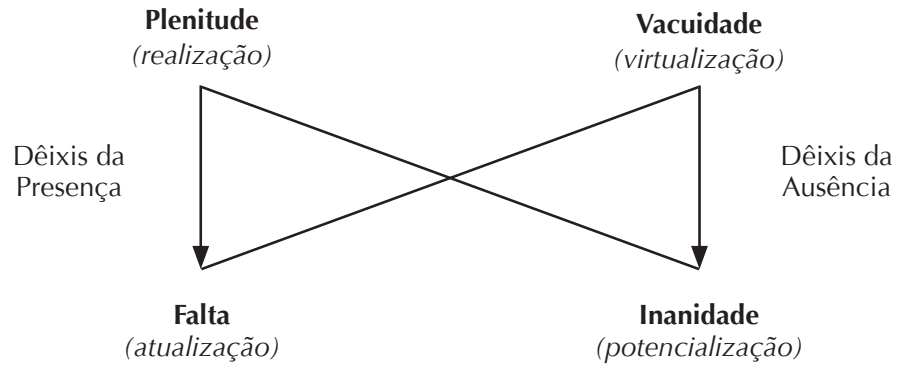

Esquema 1

Fonte: adaptado de Fontanille; Zilberberg (2001, p 134.)

\section{Entre a presença e a ausência: dois percursos da memória}

Tomando os modos da existência semiótica em sua organização sintagmática, podemos dizer que os discursos autobiográficos dão conta de dois percursos de maneira simultânea. Um deles leva da realização à virtualização, passando pela potencialização, e o outro vai da virtualização à realização, passando pela atualização. O primeiro percurso, que nomeamos como percurso do esquecimento, corresponde a uma perda de densidade existencial, que permite ao fato, inicialmente realizado, ser memorizado (potencialização), para em seguida talvez ser esquecido (virtualização), levando o sujeito a vivenciar uma espécie de vacuidade:

[...] a menor densidade existencial que um sujeito pode experimentar. Tudo indica, de fato, que o enunciador se projeta no texto como alguém que sofreu um processo de esvaziamento modal e emocional e se encontra desolado e sem elã (entenda-se por isso a ausência de direcionalidade ou, simplesmente, de intenção) (TATIT, 2010, p. 139).

No sentido contrário, temos o percurso da lembrança, em que acontece um ganho de densidade existencial, ou seja, a grandeza em questão fica mais presente para o sujeito, chegando à realização, o que provoca o sentimento de completude ou ainda de plenitude. É o que se passa durante a rememoração.

Vejamos o percurso do esquecimento: realização $\rightarrow$ potencialização $\rightarrow$ virtualização. Ele corresponde à redução da presença de uma grandeza percebida pelo sujeito em seu 
aqui e agora. Essa direção é que leva à memorização, que podemos, com Tatit, entender como uma das formas da potencialização:

Para a semiótica da presença, a memorização supõe, de um lado, o retorno dos dados realizados à condição de norma ou sistema em nosso universo cognitivo. De outro, supõe uma reabsorção da experiência sensível num quadro em que o tempo interno do sujeito, suspenso pelo choque do acontecimento, começa a se recompor até poder se reatualizar em discurso, não mais como agudeza sensorial de sua apreensão direta inicial, mas como inteligibilidade necessária para se tornar também um fato social. Por isso, dizemos que memorização em si corresponde à potencialização, combinando os aspectos átonos e tônicos da acepção do termo (ibidem, p. 154-155).

Tatit (ibidem) distingue uma potencialização átona e uma potencialização tônica. A primeira diz respeito a uma atividade contínua de assimilação dos hábitos e estereótipos. Esses elementos possuem pequena densidade de presença quando realizados, atonia que mantêm, conforme passam pelos diversos modos de presença. Ao serem "armazenados", compõem uma gramática que se realiza sob a forma de hábitos, além de propiciarem a estruturação de novas práticas significantes.

Já a potencialização tônica diz respeito àquilo que era "força, tonicidade, em realização" e que se tornou "diferença, destaque, em potencialização" (ibidem, p. 156). Os eventos marcantes podem, ao perder densidade de presença, permanecer na memória, como mostra o semioticista:

Só há uma forma de conservar a presença desse evento excepcional no campo de existência do sujeito: tirá-lo de foco e convertê-lo em potencialização. Ao perder densidade de presença, o acontecimento ganha uma zona pouco mais difusa no interior da extensidade, figurando ao lado de outros acontecimentos que diluem sua carga tensiva. Nesse estado - distensivo - o evento pode durar indefinidamente até que novas condições tornem urgente sua reconvocação (ibidem, p. 58).

Essas duas formas de memorização (potencialização átona e potencialização tônica), guardadas as devidas diferenças de quadro teórico, possuem pontos em comum com as duas memórias de que trata Bergson (2006, p. 91): a memória-hábito - "um hábito do corpo" adquirido por repetição - e a imagem-lembrança - lembrança de um momento único da vida de um sujeito. O filósofo as ilustra com uma lição aprendida de cor. A leitura repetida faz com que a lição possa ser decorada, o que diz respeito à memóriahábito: "antes hábito do que memória, ela desempenha nossa experiência passada, mas não evoca sua imagem" (ibidem, p. 176-177). Quando reflete, porém, sobre esse processo, conclui: "cada uma das leituras sucessivas volta-me então ao espírito com sua 
individualidade própria" (ibidem, p. 86), está aí o que o autor considera a "memória verdadeira": a imagem-lembrança. Bosi recupera as propostas de Henri Bergson:

O passado conserva-se e, além de conservar-se, atua no presente, mas não de forma homogênea. De um lado, o corpo guarda esquemas de comportamento de que se vale muitas vezes automaticamente na sua ação sobre as coisas: trata-se da memória-hábito, a memória dos mecanismos motores. De outro lado, ocorrem as lembranças independentes de quaisquer hábitos: lembranças isoladas, singulares, que constituiriam autênticas ressurreições do passado (BOSI, 2001, p. 48).

Podemos dizer, então, que a memorização, qualquer que seja o seu grau, diz respeito mais ao esquecimento que à lembrança, entendidos esses termos como duas figuras recorrentes do discurso autobiográfico. Na potencialização átona, as experiências são incorporadas de forma desatenta, sem que o sujeito se detenha nelas. O motorista experiente não pode lembrar-se de cada uma das operações que deve realizar para dirigir um carro.

Na potencialização tônica, é a perda de densidade de presença que faz com que grandezas intensas possam ocupar um lugar extenso na memória e, assim, durar. Se algo imprevisto e de grande impacto é vivenciado por um sujeito, como, por exemplo, um grave acidente de carro, que o motorista na hora mal consegue entender como aconteceu, é preciso que esse sujeito se reorganize de um ponto de vista subjetivo, desacelerando aquilo que veio a seu encontro rápido demais para seu entendimento e reduzindo a força com que o evento o afetou sensivelmente, pois só assim poderá conservar algo do que viveu. Logo, para que experiências que de algum modo se aproximam da noção de acontecimento (ZILBERBERG, 2007) sejam memorizadas, o sujeito precisa "esquecer", ao menos parcialmente, a força com que sobrevieram².

É o que se pode notar quando o narrador Pedro Nava fala sobre a morte do pai. Por meio da imagem de uma mão amputada a um paciente anestesiado cuja dor da falta se renova sempre, ele nos mostra a suspensão do saber no momento em que o fato se deu, devido ao grande impacto do acontecimento, e ainda a dimensão dos efeitos que a morte do pai teve ao longo de sua vida. Com "venho sofrendo" e a locução adverbial "vida inteira", revela a persistância da dor. O presente durativo (FIORIN, 1996) é utilizado aqui para mostrar os reflexos do passado em sua vida ou, ainda, como esse passado permanece ativo:

Não sei se sofri na hora. Mas sei que venho sofrendo destas horas, a vida inteira.

Ali eu estava sendo mutilado e reduzido a um pedaço de mim mesmo, sem perceber, como o paciente anestesiado que não sente quando amputam sua mão. Depois a ferida cicatriza, mas a mão perdida é dor permanente e renovada, cada vez que a intenção de um gesto não se pode completar (NAVA, 2000a, p. 376).

2 O acontecimento diz respeito àquilo que surpreende o sujeito, pois é percebido como algo que entra em seu campo de presença de forma súbita, ou seja, muito antes que se pudesse prever sua chegada. Tomado em sua integralidade pelo acontecimento, o sujeito sente seu impacto, vivenciando momentaneamente o enfraquecimento de suas competências cognitivas. 
O percurso que vai da realização à virtualização corresponde, então, a um esquecimento gradual, sendo a virtualização o momento em que a grandeza percebida está mais apagada para o sujeito, embora já incorporada a seu sistema de crenças e hábitos, ou seja, memorizada de alguma maneira. É talvez a relação tão estreita entre esquecimento e memorização que leva o antropólogo Marc Augé a afirmar que o esquecimento é a força da vida da memória, enquanto a lembrança é o seu produto:

É bem evidente que nossa memória ficaria rapidamente "saturada" se nós devêssemos conservar todas as imagens de nossa infância, em particular as da nossa primeira infância. Mas é o que resta que é interessante. E o que resta lembranças ou vestígios, iremos voltar a isso -, o que resta é o produto de uma erosão pelo esquecimento. As lembranças são esculpidas pelo esquecimento como os contornos da costa pelo mar (AUGÉ, 1998, p. 29; tradução nossa) ${ }^{3}$.

Uma das perguntas a que as reflexões do antropólogo nos remetem é se retemos em nossa memória a totalidade do passado. Essa é uma questão que pesquisadores de diversas áreas que se debruçam sobre a memória vêm debatendo com bastante afinco. A revista FAPESP de abril de 2015, por exemplo, apresenta uma pesquisa que discute a relação entre o sono e a consolidação pelo cérebro da memória de fatos recentes. De acordo com a revista, a proposta do neurocientista Sidarta Ribeiro é de que "a fixação da memória envolve tanto a ativação de alguns genes e reforço de conexões quanto a desativação de outros e eliminação de sinapses durante o sono" (ZORZETTO, 2015). O pesquisador compara esse processo ao de entalhar uma imagem em uma peça de madeira: é como se a informação nova que fica registrada fosse a parte em alto-relevo de uma figura.

Seria possível, então, abordar a questão da memorização por caminhos muito diferentes daqueles que traçamos aqui. O trabalho do estudioso do discurso consiste, porém, em examinar como isso funciona discursivamente e ainda como aparece nos textos analisados, observando o que foi selecionado - de forma consciente ou inconsciente - para compor a narrativa do passado e ainda o que foi deixado de fora, escondido ou silenciado.

É a ação reguladora do esquecimento que parece recortar aquilo que poderia constituir a totalidade do passado vivido. Assim, das numerosas experiências vividas, formam-se apenas algumas lembranças. O esquecimento, como figura discursiva, recobre, portanto, a operação de triagem, própria da sintaxe extensiva, que consiste em seleção de grandezas enumeráveis e em redução de quantidade (ZILBERBERG, 2004). É essa operação bastante abstrata que subjaz à apresentação fragmentária do passado, dado a ver muitas vezes "aos pedaços" nas obras autobiográficas. Em trecho de Baú de ossos, o narrador afirma:

3 "Il est bien évident que notre mémoire serait vite 'saturée' si nous devions conserver toutes les images de notre infance, en particulier celles de notre toute première enfance. Mais c'est ce qui reste qui est intéressant. Et ce qui reste - souvenirs ou traces, nous allons y revenir -, ce qui reste est le produit d'une érosion par l'oubli. Les souvenirs sont façonnés par l'oubli comme les contours du rivage par la mer". 
Porque esquecer é fenômeno ativo e intencional - esquecer é capítulo da memória (assim como que o seu tombo) e não sua função antagônica. [...] No que se precisa esquecer, nisto, a memória é exímia. Desvia na hora certa e suprime o couro, para evitar o divã empapado de lágrimas. Duas coisas sucedem ou são feitas no mesmo dia. Entretanto o tempo passa desigual sobre cada. Ao fim de anos, uma parece remota e a outra lateja presente e quando o acaso de nota tomada, de diário escrito, mostra-as do mesmo dia - ficamos varados de pasmo. É por isto que Proust dizia que nossa memória habitualmente não dá lembranças cronológicas (NAVA, 2000a, p. 292-294).

O esquecimento também é a concretização de operações que regulam a sintaxe intensiva: a atenuação e a minimização (ZILBERBERG, 2006, p. 95). Quando um acontecimento, vivido como experiência arrebatadora, vai deixando o campo perceptivo do sujeito para entrar "nos jamais" (NAVA, 2000a, p. 290), inicialmente, ocorre uma operação de "menos mais", uma atenuação - retira-se tonicidade. Isso pode dar lugar a um acréscimo de menos, a minimização: soma-se um "menos" àquilo que já está fraco se considerarmos o eixo da intensidade (operação de "mais menos"). Para que as grandezas selecionadas possam ser retidas e perdurar, elas precisam perder intensidade. Podemos, portanto, dizer que o esquecimento é a concretização figurativa da redução da quantidade de "coisas" (sintaxe extensiva), bem como da redução da quantidade de afeto (sintaxe intensiva).

Nas obras autobiográficas, como Baú de ossos (ibidem), o percurso do esquecimento é construído no narrado. Aquilo que para o menino recordado é vivido como grandeza realizada passa sucessivamente para a potencialização e, em seguida, para a virtualização, responsável pela vacuidade existencial. Essa é a direção que leva à seleção e ao enfraquecimento das grandezas no campo de presença desse sujeito. Vale a pena insistir que é justamente a saída do modo realizado que permite a entrada na memória, sob a forma da memorização, posta "em cena" em diversas passagens:

[...] menino, moreno, tímido, meio sonso que se esgueirava entre os grandes e gostava de ficar pelos cantos olhando tudo, ouvindo tudo, guardando tudo, tudo. Armazenando na memória (seu futuro martírio) os fragmentos de um presente jamais apanhável, mas que ele sedimentava e ia socando quando eles caíam mortos e virados no passado de cada instante (ibidem, p. 228).

Retomemos agora o percurso da lembrança: virtualização $\rightarrow$ atualização -> realização. Ele corresponde a um ganho de densidade existencial: aquilo que havia se tornado presença memorizada (potencialização) e depois presença esquecida (virtualização), por um estímulo do mundo presente, provoca no sujeito o sentimento de falta e, desse modo, a necessidade de recuperação da presença (atualização), até retornar ao presente do discurso autobiográfico como lembrança narrada (realização). O sujeito pode, então, experimentar o sentimento de plenitude, ainda que por um breve momento. 
Não é, no entanto, o vivido que retorna, mas uma imagem, um simulacro, que carrega valores que o sujeito recordador acredita serem semelhantes aos investidos nas experiências passadas: está aí a lembrança.

É importante enfatizar ainda que os valores atrelados às lembranças do passado podem apresentar-se como repulsivos ou atrativos para aquele que se recorda. Não são todos os narradores de obras autobiográficas que se mostram saudosos, como comprovam Infância (2003), de Graciliano Ramos, ou Meus verdes anos (1987), de José Lins do Rego.

As operações sintáticas que constituem as saídas e entradas de grandezas no campo de presença do sujeito recordador ficam, de certa forma, registradas. Essas operações alteram seu sistema de crenças e valores, assim como suas expectativas, permitindo distinguir entre aquilo que acredita ter vivido e as experiências presentes. Bergson afirma algo na mesma direção, embora em um quadro teórico evidentemente diverso, quando reflete sobre as diferenças entre a percepção presente e a memória:

Pouco a pouco aparece como que uma nebulosidade que se condensasse; de virtual ela passa ao estado atual; e à medida que seus contornos se desenham e sua superfície se colore, ela tende a imitar a percepção. Mas continua presa ao passado por suas raízes profundas, e se, uma vez realizada, não se ressentisse de sua virtualidade original, se não fosse, ao mesmo tempo que um estado presente, algo que se destaca do presente, não a reconheceríamos jamais como uma lembrança (ZILBERBERG, 2006, p. 156).

Nos gêneros autobiográficos, é a escritura que possibilita a passagem das lembranças, sob o modo atualizado, à realização. A narrativa das memórias faz com que o esquecido seja atualizado por meio da lembrança e se realize "novamente" ao ser textualizado. É esta direção, da ausência para a presença, que diz respeito à rememoração, que pode atingir aquele que se lembra com diversos graus de impacto.

Quando o adulto Pedro Nava docemente mastiga a batida feita por sua avó, é como se as figuras que povoaram sua infância ressurgissem diante de seus olhos. Conforme mostramos no início deste artigo, no comentário ao fragmento que retrata essa experiência, trata-se de um trecho em que a presentificação do passado, dada pela sintaxe temporal, somada ao apelo aos sentidos e à predominância da coordenação na organização dos períodos e das orações revelam um narrador tomado por completo por suas lembranças. Ele vê novamente aquilo que o menino via ou ainda vê junto com o menino. É como se uma espécie de sincretismo de pontos de vista fosse experimentada momentaneamente ou, ainda como se seus campos de presença pudessem ser sobrepostos por um breve instante. É diferente do que encontramos na passagem apresentada a seguir, em que o narrador conta sobre os passeios que realizava com tio Salles em seus tempos de criança: 
Ainda com tio Salles subi um dia as ladeiras da Rua do Morro, onde morava não sei mais que amigo seu. Enquanto ele parava, no alto, para olhar a vista escampada e larga que dali se descortina - Santa Teresa, o Corcovado e a Tijuca levantando a cara e o nariz pico - eu atentei num pano de muro branco todo cheio de inscrições e desenhos pornográficos. [...] Tal era o esboço que vi - que guardei de memória, como coisa perturbadora, posto que então incompreensível (NAVA, 2000a, p. 369).

Embora retrate um momento marcante para o menino e que, por isso, pôde ser retido na memória, quando relembra esse momento, o narrador se mostra menos arrebatado do que ao saborear o doce preparado pela avó. É o efeito que se depreende do uso recorrente da subordinação; da predominância, no que diz respeito à sintaxe temporal, do pretérito perfeito 2 e do imperfeito (tempos que expressam concomitância com relação a um momento de referência passado); e de uma pontuação que recorta mais as sentenças - se compararmos com aquela utilizada na parte relativa à "batida" -, como se interrompendo o fluxo da memória. Todos esses elementos contribuem para construir a cena a partir do ponto de vista da criança, apresentado como distinto daquele do narrador. Logo, trata-se de uma experiência de rememoração que possui um impacto menor sobre o narrador que aquela provocada pelo sabor da batida, que faz o passado desfilar diante de seus olhos como "a projeção (no vácuo!) de um filme de cinema mudo" (ibidem, p. 27).

Enfim, do mesmo modo que a memorização está sob a égide do esquecimento, correspondente à diminuição da densidade de presença de determinada grandeza, na rememoração, que diz respeito ao aumento da densidade de presença daquilo que se acredita que estava esquecido, entra em jogo a lembrança, como a imagem resultante desse processo. Nos discursos autobiográficos, ocorre que esquecimento e memorização, de um lado, e rememoração e lembrança, de outro, parecem atuar de forma simultânea, embora em níveis diferentes do discurso.

Como vimos em Nava, no tempo da narração, conforme o narrador relata suas memórias, rememora o passado adormecido e materializa as lembranças desse passado no texto. Conduz-nos, desse modo, da dêixis da ausência para a da presença. Entretanto, na história que ele conta, as experiências vividas pelo sujeito do narrado - o menino caminham sucessivamente no sentido contrário, da presença para a ausência, adentrando o esquecimento e também a memória. Nesse sentido, reconhecemos como algo essencial para a constituição dos discursos autobiográficos esse entrelaçamento complexo de dois percursos distintos, estabelecidos entre a presença e a ausência, que faz com que a plenitude experimentada na realização coocorra sempre (ainda que em outro nível) com o vazio de sentido imposto pela virtualização. Talvez esteja aí uma das origens dessa espécie de "sabor agridoce" que sentimos, como leitores, diante de obras autobiográficas. 
Mariana Luz Pessoa de Barros é doutora em Semiótica e Linguística Geral pela USP. Realizou estágio de doutoradosanduíche na Université Paris 8, sob supervisão de Denis Bertrand; atuou como professora de linguística e semiótica na graduação e na pós-graduação e como professora de língua portuguesa no ensino fundamental II e no ensino médio. É membro do Grupo de Estudos Semióticos da USP (Ges-USP), coordenadora do Fórum de Atualização em Pesquisas Semióticas (FAPS-USP) e faz parte da Comissão Editorial da Revista Estudos Semióticos. Atualmente, desenvolve o projeto de pós-doutorado "Memória, ciência e educação: um estudo discursivo dos memoriais acadêmicos" (USP).

maluzpessoa@hotmail.com

\section{Referências}

AUGÉ, M. Les formes de l'oubli. Paris: Éditions Payot et Rivages, 2001.

BERGSON, H. Matéria e memória: ensaio sobre a relação do corpo com o espírito. Tradução de P. Neves. São Paulo: Martins Fontes, 2006.

BERTRAND, D. Caminhos da semiótica literária. Tradução do Grupo Casa. Bauru: Editora da Universidade do Sagrado Coração, 2003.

BOSI, E. Memória e sociedade: lembranças de velhos. São Paulo: Companhia das Letras, 2001

FIORIN, J. L. As astúcias da enunciação. São Paulo: Ática, 1996.

Semiótica e comunicação. Revista Galáxia, São Paulo, n. 18, p.13-30, 2004.

FONTANILLE, J.; ZILBERBERG, C. Tensão e significação. Tradução de I. C. Lopes, L. Tatit e W. Beividas. São Paulo: Discurso Editorial/Humanitas, 2001.

NAVA, P. Baú de ossos. São Paulo: Ateliê, 2000a.

Balão cativo. São Paulo: Ateliê, 2000b.

RAMOS, G. Infância. Rio de Janeiro/São Paulo: Record, 2003.

REGO, J. L. Ficção completa. Rio de Janeiro: José Olympio, v. 2, 1987.

TATIT, L. Semiótica à luz de Guimarães Rosa. São Paulo: Ateliê, 2010.

ZILBERBERG, C. As condições semióticas da mestiçagem. Tradução de I. C. Lopes e L. Tatit. In: Cañizal, Eduardo Peñuela; Caetano, Kati Eliana (org.). O olhar à deriva: mídia, significação e cultura. São Paulo: Annablume, 2004. p. 69-101.

Eléments de grammaire tensive. Limoges: Pulim, 2006. 
Louvando o acontecimento. Tradução de M. L. V. P. Diniz. Revista Galáxia, São Paulo, n. 13, pp.13-28, 2007.

ZORZETTO, R. Os relevos da memória. Revista Pesquisa FAPESP, São Paulo, ed. 230, abril, 2015. Disponível em: <http://revistapesquisa.fapesp.br/2015/04/10/os-relevos-da-memoria/>. Acesso em: 01 dez. 2015.

Artigo recebido em dezembro de 2015 e aprovado em janeiro de 2016. 